\title{
Acquisition of iron from host sources by mesophilic Aeromonas species
}

\author{
George Massad, Jean E. L. Arceneaux and B. Rowe Byers* \\ Department of Microbiology, University of Mississippi Medical Center, 2500 North State Street, Jackson, \\ Mississippi 39216, USA
}

(Received 5 June 1990; revised 1 October 1990; accepted 8 October 1990)

\begin{abstract}
The mesophilic Aeromonas species are opportunistic pathogens that produce either of the siderophores amonabactin or enterobactin. Acquisition of iron for growth from Fe-transferrin in serum was dependent on the siderophore amonabactin; 50 of 54 amonabactin-producing isolates grew in heat-inactivated serum, whereas none of 30 enterobactin-producing strains were able to grow. Most isolates (regardless of siderophore produced) used haem as a sole source of iron for growth; all of 33 isolates grew with either haematin or haemoglobin and $\mathbf{3 0}$ of these used haemoglobin when complexed to human haptoglobin. Mutants unable to synthesize a siderophore used iron from haem, suggesting that this capacity was unrelated to siderophore production. Some members of the mesophilic Aeromonas species have evolved both siderophore-dependent and -independent mechanisms for acquisition of iron from a host.
\end{abstract}

\section{Introduction}

Competition for iron between a vertebrate host and an invading micro-organism is one of the points on which the outcome of an infection is balanced. The absolute nutritional requirement of most bacteria for the metal means that the microbe cannot establish itself without overcoming the host's iron-witholding defences. Transferrin is responsible for the iron-limiting bacteriostatic activity of serum, although some pathogenic bacteria use Fe-transferrin as a source of the metal. Certain siderophores (microbial iron transport cofactors) are able to chelate iron from Fe-transferrin. Production of the siderophores aerobactin and anguibactin is crucial for virulence of pathogenic Escherichia coli and Vibrio anguillarum, respectively (Crosa, 1984; Carbonetti et al., 1986). Because they produce cell surface transferrin receptors, the pathogenic Neisseria species can derive iron directly from Fe-transferrin without intervention of a siderophore (West \& Sparling, 1985).

Haem, primarily in the form of haemoglobin, is another potential source of iron to an invading microbe. To access iron in haem, cytolytic (haemolytic) destruction of host cells may be required. This may account in part for the importance of haemolysins in virulence (Marre et al., 1986; Chakraborty et al., 1987; Kathariou et al., 1987). Many haemolysins are regulated by iron,

\footnotetext{
Abbreviation: EDDA, ethylenediamine-di(o-hydroxyphenylacetic acid).
}

their synthesis being increased by iron starvation (Riddle et al., 1981 ; Lebeck \& Gruenig, 1985; Stoebner \& Payne, 1988). Free haemoglobin and haem should be scarce in the sera of vertebrates because these compounds are complexed by the serum proteins haptoglobin and haemopexin, respectively (Muller-Eberhard, 1970; Sutton, 1970). Association of haemoglobin with haptoglobin prevents use of haem iron by E. coli (Eaton et al., 1982) suggesting an iron-withholding defence function for haptoglobin, although certain other bacteria readily acquire iron from haemoglobin-haptoglobin complexes (Francis et al., 1985; Dyer et al., 1987; Stull, 1987; Zakaria-Meehan et al., 1988). Haemopexin and albumin bind haem, preventing use of haem iron by species of Neisseria (Dyer et al., 1987) but not by Haemophilus influenzae (Stull, 1987).

The mesophilic Aeromonas species are opportunistic Gram-negative pathogens that cause diseases in hosts ranging from fish to man (Khardori \& Fainstein, 1988). The haemolysin(s) of $A$. hydrophila have been shown to be iron regulated (Riddle et al., 1981) and to be important in virulence (Chakraborty et al., 1987). Most isolates produce one of two siderophores, either enterobactin or amonabactin; a few produce no siderophore (Barghouthi et al., 1989a; Zywno et al., 1989). The mechanism by which these extracellular pathogens obtain iron from a vertebrate host is not known; therefore, the purpose of the present study was to determine the capacities of the mesophilic aeromonads to use Fe-transferrin and various haem-proteins as sole iron sources. 


\section{Methods}

Bacteria. Strains of Aeromonas hydrophila, A. sobria and A. caviae (isolated from clinical and environmental sources) were obtained from C. Lobb, J. Bertolini and S. Stuart of this institution. S. Zywno, USFDA Laboratory, Dauphin Island, Alabama, L. Pickering, University of Texas Health Science Center, Houston, and L. Ford, Louisiana State University, Baton Rouge, also supplied strains. An amonabactin mutant, A. hydrophila SB22, was supplied by S. Barghouthi of this institution. It was constructed by marker exchange mutagenesis of wild-type $A$. hydrophila 495A2 with the transposon-inactivated amonabactin biosynthetic gene AmoA::Tn5 (Barghouthi et al., $1989 c$ ). An enterobactin mutant, $A$. hydrophila GM89, was generated by chemical mutagenesis and isolated as previously described (Barghouthi et al., 1989b). Cultures were kept at $-70{ }^{\circ} \mathrm{C}$ in $20 \%$ (v/v) glycerol in nutrient broth (Difco). The type of siderophore produced by these strains was reported previously (Zywno et al., 1989).

Sources and treatment of sera. Pooled human serum (obtained from Mississippi Blood Products, Jackson) and pooled channel catfish (Ictalurus punctatus) serum (collected by venipuncture) were heatinactivated at $56{ }^{\circ} \mathrm{C}$ for $30 \mathrm{~min}$ (to destroy complement activity) and were then filter sterilized (Millipak 40, $0 \cdot 22 \mu \mathrm{m}$ pore size, Millipore). Human complement serum was purchased from Sigma. Channel catfish complement serum was prepared from blood collected by venipuncture of healthy fish and was filter sterilized (Millex-GV, $0.22 \mu \mathrm{m}$ pore size, Millipore). All sera were stored at $-70^{\circ} \mathrm{C}$; before use they were slowly thawed and unused portions were discarded.

Assay for growth in heat-inactivated serum. Overnight cultures of the test strains in nutrient broth were diluted in potassium phosphate buffered saline (10 mM-potassium phosphate, $0.15 \mathrm{M}-\mathrm{NaCl}, \mathrm{pH} 7.4$ ) and were used to inoculate $1 \mathrm{ml}$ of serum at an initial level of $10^{3} \mathrm{c}$.f.u. $\mathrm{ml}^{-1}$. After incubating this culture overnight at $37^{\circ} \mathrm{C}, \mathrm{OD}_{600}$ was determined. An $\mathrm{OD}_{600} \geq 0.2$ was considered positive for growth. For some determinations, iron $\left(5 \mu \mathrm{g} \mathrm{ml}^{-1}\right)$ or amonabactin $\left(1 \mu \mathrm{g} \mathrm{ml}^{-1}\right)$ was added to the cultures. Viable cell counts were determined by plating dilutions of the cultures onto Luria agar.

Preparation of host haem compounds. Haematin, human haemoglobin and human haptoglobin (phenotypes 1, 2, and 2-1) were purchased from Sigma. Channel catfish haemoglobin was obtained from freshly collected blood. The erythrocytes were separated from the plasma by centrifugation and washed three times with phosphate-buffered saline. The erythrocytes were lysed and the amount of haemoglobin in the lysate was determined spectrophotometrically from the $A_{540}$ by comparison with known concentrations of human haemoglobin. Haemoglobin-haptoglobin complexes were formed by incubating $2 \mathrm{ml}$ human haemoglobin $\left(0.25 \mathrm{mg} \mathrm{ml}^{-1}\right)$ with $1 \mathrm{mg}$ haptoglobin.

Host haem compound utilization assay. To determine which host haem compounds could be utilized as iron sources by isolates of the Aeromonas species, the following assay was employed. Iron deficient L-EDDA agar was prepared by adding EDDA [ethylenediamine-di (o-hydroxyphenylacetic acid); Sigma] at a final concentration of $0.5 \mathrm{mg}$ $\mathrm{ml}^{-1}$ to Luria agar. Overnight cultures were inoculated into molten L-EDDA agar at a density of $10^{4}$ c.f.u. $\mathrm{ml}^{-1}$. Compounds to be tested were impregnated on paper disks (that had been washed with $25 \mathrm{~mm}$ EDTA and water) which were placed on the seeded agar plates. Plates were incubated and examined at 24 and $48 \mathrm{~h}$ for zones of growth surrounding the disks.

Assay for resistance to the bactericidal activity of complement sera. A modification of the microcolorimetric serum resistance assay of Moll et al. (1979) was used to measure resistance of the isolates to complement lysis. This assay is based on the fact that lysis by complement is immediately bactericidal, abolishing a micro-organism's capacity to metabolize a substrate such as glucose. Therefore, resistance to complement lysis may be assessed by determining the capacity to metabolize glucose in the presence of serum. An overnight culture of each isolate in nutrient broth was diluted $(1: 10)$ into $200 \mu \mathrm{l}$ nutrient broth in the well of a microtitre plate (Linbro, $12 \times 8$ flat bottom, Flow Laboratories). After $3 \mathrm{~h}$ incubation, this exponential-phase culture was diluted $(1: 10)$ into microtitre wells containing $200 \mu \mathrm{l}$ PGB medium [ $1 \%$ $(w / v)$ peptone, $1 \%(w / v)$ glucose and $0.0075 \%$ bromocresol purple], and PGB medium containing 30\% (v/v) serum (PGBS). After incubating for 4-5 h, the $A_{414}$ of each well was determined with a microtitre plate reader (Titertek, Flow Laboratories). Using bromocresol purple instead of the previously recommended bromothymol blue (Moll et al., 1979) prevented interference from culture turbidity, allowing $A_{414}$ to represent colour change and not increase in culture turbidity. When heat-inactivated serum was used in this assay, all of the 198 strains responded as if resistant to lysis, confirming that the assay was an accurate measure of the sensitivity of a strain to complement lysis.

\section{Results}

\section{Utilization of $\mathrm{Fe}$-transferrin in serum}

The capacity of Aeromonas species to use Fe-transferrin as a sole iron supply was determined by measuring growth in heat-inactivated serum. Of 54 amonabactinproducing isolates tested, 50 grew in heat-inactivated human serum, whereas none of 30 enterobactin-producing strains were able to grow (Table 1). Adding $5 \mu \mathrm{g}$ iron $\mathrm{ml}^{-1}$ to the heat-inactivated serum permitted growth of all isolates, demonstrating that inhibition was due to iron restriction. Moreover, the heat-inactivated serum was only bacteriostatic for those isolates unable to grow, because plate counts revealed no significant loss of viable cells at $24 \mathrm{~h}$ after inoculation (initially, $3.0 \times 10^{3}$ c.f.u. $\mathrm{ml}^{-1}$; at $24 \mathrm{~h}, 6.9 \times 10^{3}$ c.f.u. $\mathrm{ml}^{-1}$ ). The four amonabactin-producing isolates that did not grow in serum belonged to the species $A$. caviae (Table 1). An amonabactin mutant, $A$. hydrophila SB22, did not grow in heatinactivated human or catfish serum; however, supple-

\section{Table 1. Utilization of human Fe-transferrin as a sole iron source by mesophilic Aeromonas species}

Growth assays were done twice and are expressed as no. isolates positive/no. isolates tested.

\begin{tabular}{lcc}
\hline \hline & \multicolumn{2}{c}{ Growth in heat-inactivated serum } \\
\cline { 2 - 3 } \multicolumn{1}{c}{ Species } & $\begin{array}{c}\text { Siderophore produced: } \\
\text { Amonabactin }\end{array}$ & Enterobactin \\
\hline A. hydrophila & $32 / 32$ & $0 / 5$ \\
A. sobria & $5 / 5$ & $0 / 25$ \\
A. caviae & $13 / 17$ & - \\
Totals & $50 / 54$ & $0 / 30$ \\
\hline \hline
\end{tabular}

* No isolates were available when assays were done. 
Table 2. Requirement for iron or amonabactin for growth in heat-inactivated serum

Representative data are shown; three experiments were performed for both human and catfish serum.

\begin{tabular}{lccc}
\hline \hline & \multicolumn{2}{c}{$\begin{array}{c}\text { Growth }\left(\mathrm{OD}_{600}\right) \text { in heat-inactivated serum } \\
\text { supplemented with:* }\end{array}$} \\
\cline { 2 - 4 } $\begin{array}{l}\text { A. hydrophila } \\
\text { strain }\end{array}$ & No supplement & Iron & Amonabactin \\
\hline 495A2 & 1.02 & ND & ND \\
SB22 & 0.00 & 2.66 & 0.471 \\
\hline
\end{tabular}

ND, Not determined.

*Iron $\left(5 \mu \mathrm{g} \mathrm{ml}^{-1}\right)$ was added as $\mathrm{FeCl}_{3}$; amonabactin was added at $1 \mu \mathrm{g} \mathrm{ml} \mathrm{m}^{-1}$.

mentation with $1 \mu \mathrm{g}$ amonabactin $\mathrm{ml}^{-1}$ or with $5 \mu \mathrm{g}$ iron $\mathrm{ml}^{-1}$ allowed growth (Table 2).

\section{Utilization of host haem compounds as sole iron sources}

To determine if isolates of the mesophilic Aeromonas species could use various host haem compounds, we assayed the capacity of these compounds to reverse growth inhibition due to iron starvation. All of 33 isolates tested (representing both amonabactin- and enterobactin-producing strains) used either haematin or haemoglobin (human or catfish) as a source of iron (Table 3). Because human serum contains the haemoglobin-binding protein haptoglobin, complexes of haemoglobin with the three human haptoglobin phenotypes were also tested. Most isolates used haemoglobin associated with all three haptoglobin types, although one isolate of each species was unable to use any of the phenotypes. One strain (A. hydrophila 131$)$ used types 1 and 2 but failed to grow with the heterozygous type 2-1 (Table 3).

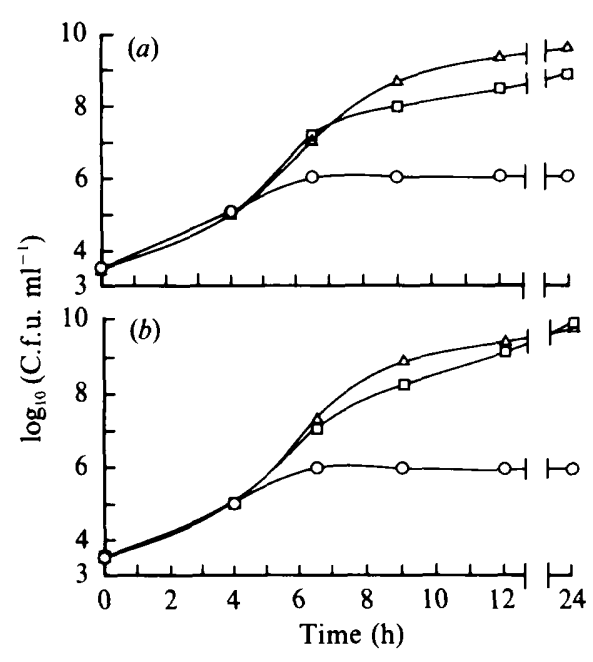

Fig. 1. Use of haemoglobin or haemoglobin-haptoglobin by the amonabactin mutant $A$. hydrophila $\operatorname{SB} 22(a)$ and the enterobactin mutant $A$. hydrophila GM89 (b) for growth in Luria broth containing $0.1 \mathrm{mg} \mathrm{EDDA} \mathrm{ml} \mathrm{m}^{-1}$ with no addition (O); $50 \mu \mathrm{g}$ haemoglobin $\mathrm{ml}^{-1}$ $(\triangle)$; or haemoglobin-haptoglobin complexes containing $50 \mu \mathrm{g}$ haemoglobin $\mathrm{ml}^{-1}$ and $100 \mu \mathrm{g}$ haptoglobin $\mathrm{ml}^{-1}(\square)$. The data shown are representative growth curves from replicate experiments.

To assess the role of siderophores in the use of haemproteins as iron sources, the siderophore mutants $(A$. hydrophila SB22, an amonabactin mutant; and $A$. hydrophila GM89, an enterobactin mutant) were tested for their ability to use these iron sources in an irondeficient rich medium (Luria broth supplemented with EDDA). Both mutants were able to grow only when supplemented with either haemoglobin or haemoglobinhaptoglobin complexes (Fig. 1).

\section{Resistance to serum complement bactericidal activity}

Of 88 amonabactin-producing isolates, $70(80 \%)$ were

Table 3. Utilization of host haem compounds as sole iron sources by mesophilic Aeromonas species

Growth assays were done three times and are expressed as the number of isolates able to grow on each haem source.

\begin{tabular}{lcccccc}
\hline & & \multicolumn{4}{c}{ Growth on haem source indicated } \\
\cline { 3 - 7 } & & & & \multicolumn{3}{c}{ Haemoglobin-haptoglobin } \\
\cline { 3 - 7 } \multicolumn{1}{c}{ Species } & $\begin{array}{c}\text { Total } \\
\text { no. of } \\
\text { isolates }\end{array}$ & Haematin & Haemoglobin* & 1 & $2-1$ \\
\hline A. hydrophila & 21 & 21 & 21 & 20 & 19 & 20 \\
A. sobria & 9 & 9 & 9 & 8 & 8 & 8 \\
A. caviae & 3 & 3 & 3 & 2 & 2 & 2 \\
\hline \hline
\end{tabular}

* Human or catfish haemoglobin. 
Table 4. Association of siderophore type and resistance to the bactericidal action of human complement serum

Numbers in parentheses are no. of resistant isolates/no. of isolates tested.

\begin{tabular}{llc}
\hline \hline & \multicolumn{2}{c}{ Resistant isolates $(\%)$} \\
\cline { 2 - 3 } \multicolumn{1}{c}{ Species } & \multicolumn{2}{c}{ Siderophore produced: } \\
& Amonabactin & Enterobactin \\
\hline A. hydrophila & $90(56 / 62)$ & $15(2 / 13)$ \\
A. sobria & $80(4 / 5)$ & $49(42 / 86)$ \\
A. caviae & $47(10 / 21)$ & $-*$ \\
All isolates $\dagger$ & $80(70 / 88)$ & $44(44 / 99)$ \\
\hline \hline
\end{tabular}

* No isolates were available when assays were done.

$+P<0.00001$ by chi-square test comparing resistance of enterobactin and amonabactin producers.

resistant to the immediate bactericidal action of complement while only $44 \%$ of 99 enterobactin-producing isolates were similarly resistant (Table 4). Chi-square analysis revealed that this difference was statistically significant $(P<0 \cdot 00001)$, suggesting that the probably independent traits of amonabactin synthesis and complement resistance tend to occur together. Like the parent strain, the amonabactin mutant $A$. hydrophila SB22 retained resistance to complement lysis. Human complement serum and channel catfish complement serum gave identical results with all strains.

\section{Discussion}

Vertebrate serum is a complex material containing the respectively microbiostatic and microbicidal components transferrin and complement. The capacity of a micro-organism to use Fe-transferrin as an iron supply can be measured in a defined bacteriological medium to which purified $\mathrm{Fe}$-transferrin is added, but the results may be misleading. Some siderophores may be inactivated by components of vertebrate serum. For example, serum albumin binds to the siderophore enterobactin and renders it nonfunctional; the siderophore aerobactin is unaffected by albumin (Konopka \& Neilands, 1984). To approximate more closely to the situation in an animal host, we determined microbial use of $\mathrm{Fe}$ transferrin as an iron source by measuring bacterial growth in human serum heated to destroy its complement activity. Growth of the Aeromonas species in heatinactivated human serum was absolutely dependent on amonabactin production, suggesting that amonabactin mediated the use of Fe-transferrin. The fact that the enterobactin-producing strains were unable to grow in heat-inactivated serum confirms the finding that entero- bactin is not functional in serum (Konopka \& Neilands, 1984). The mesophilic aeromonads probably lack a system for the direct use (without a siderophore) of Fetransferrin, because the amonabactin mutant $A$. hydrophila SB22 required added amonabactin or iron for growth in heat-inactivated serum. Aeromonas species were also able to use a variety of haem compounds as sources of iron. The finding that both the amonabactin and enterobactin mutants were able to use haem compounds indicated that use of haem as an iron source was siderophore-independent. Binding of haemoglobin by haptoglobin protected the haem moiety from utilization by a few isolates, supporting the proposition that haptoglobin may have bacteriostatic activity for some microbes (Eaton et al., 1982). It can be predicted that an isolate producing enterobactin must rely on its ability to use haem as an iron source during an infection. The cytolysins/haemolysins necessary for the release of haem compounds from host cells may also be crucial for the virulence of enterobactin-producing strains.

In addition to the iron-limiting bacteriostatic activity imposed by transferrin, vertebrate serum also contains complement which has an immediate bactericidal lytic action on many bacteria. For the strains that we tested, the group that produce amonabactin were statistically $(P$ $<0.00001$ ) more resistant to complement lysis than the enterobactin-producing strains. Resistance of Aeromonas species to complement lysis has been related to a protein surface array (S-layer) and to lipopolysaccharide (Munn et al., 1982; Dooley \& Trust, 1988).

In summary, certain members of the mesophilic Aeromonas species have evolved two separate systems for acquisition of host iron. One of these is siderophoremediated and accesses iron in Fe-transferrin; however, of the two siderophores made by different isolates of the aeromonads, only amonabactin functions in the serum environment. Most isolates also use (by a siderophoreindependent process) various haem compounds as sole iron sources. Whether either or both of these alternative methods of iron acquisition are used during an infection remains unknown.

We are grateful to S. Barghouthi, E. Meydrich, S. Zywno and J. Bertolini for advice and essential help. We appreciate the many colleagues who kindly provided strains. This research was supported by Public Health Services grant AI24535 from the National Institute of Allergy and Infectious Diseases.

\section{References}

Barghouthi, S., Young, R., Olson, M. O. J., Arceneaux, J. E. L., Clem, L. W. \& Byers, B. R. (1989a). Amonabactin, a novel tryptophan- or phenylalanine-containing phenolate siderophore in Aeromonas hydrophila. Journal of Bacteriology 171, 1811-1816. 
Barghouthi, S., Young, R., Arceneaux, J. E. L. \& Byers, B. R. $(1989 \mathrm{~b})$. Physiological control of amonabactin biosynthesis in Aeromonas hydrophila. Biology of Metals 2, 155-160.

Barghouthi, S., Arceneaux, J. \& Byers, R. (1989c). Cloning and transposon mutagenesis of a siderophore (amonabactin) gene from Aeromonas hydrophila. In Abstracts of the Annual Meeting of the American Society for Microbiology D214, p. 118.

Carbonetti, N. H., Boonchai, S., Parry, S. H., Vaisanen-Rhen, V., Korhonen, T. K. \& Williams, P. H. (1986). Aerobactin-mediated iron uptake by Escherichia coli isolates from human extraintestinal infections. Infection and Immunity 51, 966-968.

Chakraborty, T., Huhle, B., Hof, H., Bergaauer, H. \& Goebel, W. (1987). Marker exchange mutagenesis of the aerolysin determinant in Aeromonas hydrophila demonstrates the role of aerolysin in $A$. hydrophila-associated systemic infections. Infection and Immunity $\mathbf{5 5}$, 2274-2280.

Crosa, J. H. (1984). The relationship of plasmid-mediated iron transport and bacterial virulence. Annual Review of Microbiology 38, 68-89.

DoOley, J. S. G. \& TRUST, T. J. (1988). Surface protein composition of Aeromonas hydrophila strains virulent for fish: identification of a surface array protein. Journal of Bacteriology 170, 499-506.

Dyer, D. W., West, E. P. \& SParling, P. F. (1987). Effects of serum carrier proteins on the growth of pathogenic Neisseriae with hemebound iron. Infection and Immunity 55, 2171-2175.

Eaton, J. W., Brandt, P., Mahoney, J. R. \& Lee, J. T. (1982). Haptoglobin: a natural bacteriostat. Science 215, 691-693.

FRANCIS, R. T., JR, BOOTH, J. W. \& BECKER, R. R. (1985). Uptake of iron from hemoglobin and the hemoglobin-haptoglobin complex by hemolytic bacteria. Journal of Biochemistry 17, 767-773.

Kathariou, S., Metz, P., hof, H. \& Goebel, W. (1987). Tn916induced mutations in the hemolysin determinant affecting virulence of Listeria monocytogenes. Journal of Bacteriology 169, 1291-1297.

K hardori, N. S. \& FAInStein, V. (1988). Aeromonas and Plesiomonas as etiological agents. Annual Review of Microbiology 42, 395-419.

KonopKa, K. \& NeIlandS, J. B. (1984). Effect of serum albumin on siderophore-mediated utilization of transferrin iron. Biochemistry 23, $2122-2127$.
Lebeck, G. \& GrueniG, H. (1985). Relation between the hemolytic property and iron metabolism in Escherichia coli. Infection and Immunity 50, 682-686.

Marre, R., Hacker, J., Henkel, W. \& Goebel, W. (1986). Contribution of cloned virulence factors from uropathogenic Escherichia coli to nephropathogenicity in an experimental rat pyelonephritis model. Infection and Immunity 54, 761-767.

Moll, A., Cabello, F. \& Timmis, K. N. (1979). Rapid assay for the determination of bacterial resistance to the lethal activity of serum. FEMS Microbiology Letters 6, 273-276.

MUlLER-EberhaRd, U. (1970). Hemopexin. New England Journal of Medicine 283, 1090-1094.

Munn, C. B., Ishiguro, E. E., Kay, W. W. \& Trust, T. J. (1982). Role of surface components in serum resistance of virulent Aeromonas salmonicida. Infection and Immunity 36, 1069-1075.

Riddle, L. M., Graham, T. E. \& AmborSKI, R. L. (1981). Medium for the accumulation of extracellular hemolysin and protease by Aeromonas hydrophila. Infection and Immunity 33, 728-733.

Stoebner, J. A. \& PAYNe, S. M. (1988). Iron-regulated hemolysin production and utilization of heme and hemoglobin by Vibrio cholerae. Infection and Immunity 56, 2891-2895.

Stull, T. L. (1987). Protein sources of heme for Haemophilus influenzae. Infection and Immunity 55, 148-153.

SutTon, H. E. (1970). The haptoglobins. Progress in Medicine and Genetics 7, 163-215.

West, S. E. H. \& SParling, P. F. (1985). The response of Neisseria gonorrhoeae to iron limitation: alterations in the expression of membrane proteins without apparent siderophore production. Infection and Immunity 47, 388-394.

Zakaria-Meehan, Z., Massad, G., Simpson, L. M., Travis, J. C. \& OLIVER, J. D. (1988). Ability of Vibrio vulnificus to obtain iron from hemoglobin-haptoglobin complexes. Infection and Immunity 56, 275277.

Zywno, S., Bailey, C., Arceneaux, J. \& Byers, R. (1989). Siderophore distribution in isolates of the Aeromonas species. In Abstracts of the Annual Meeting of the American Society for Microbiology D91, p. 97. 